\title{
FORTHCOMING PAPERS
}

The following are some papers that have been accepted for publication in future issues of Clays and Clay Minerals:

Rama kumar Allada, Edward Peltier, Alexandra Navrotsky, William H. Casey, Annette Johnson, Hillary Thompson Berbeco and Donald L. Sparks. Calorimetric determination of the enthalpies of formation of hydrotalcite-like solids and their use in the geochemical modeling of metals in natural waters

Xiaofei Tian, Min Wei, David G. Evans and Guoying Rao. Controlled polymerization of metanilic anion within the interlayer of NiAl layered double hydroxide

Michael G. Roberts, Hui Li, Brian J. Teppen and Stephen A. Boyd. Sorption of nitroaromatics by ammonium- and organic ammonium-exchanged smectite shifts from adsorption/complexation to a partition-dominated process

Rodney G. Harris, Bruce B. Johnson and John D. Wells. Studies on the adsorption of dyes to kaolinite

Rodney G. Harris, Bruce B. Johnson and John D. Wells. Competitive adsorption of cadmium and dyes to kaolinite

Rodney G. Harris, John D. Wells, Michael J. Angove and Bruce B. Johnson. Modeling the adsorption of organic dye molecules to kaolinite
Fabienne Favre, Joseph W. Stucki and Pascal Boivin. Redox properties of structural iron in ferruginous smectite. A discussion about the standard potential and its environmental implications

Emmanuel Joussein, Sabine Petit, Claire-Isabelle Fialips, Philippe Vieillard and Dominique Righi. Differences in the dehydration-rehydration behavior of halloysites: new evidence and interpretations

Ai-ping Wang, Feiyu Kang, Zheng-Hong Huang and Zhancheng Guo. Preparation of porous carbons from halloysite-sucrose mixtures

Mervat S. Hassan and Hassan M. Baioumy. Structural and chemical alteration of glauconite under progressive acid treatment

Andrew C. Aplin, Ingo F. Matenaar, Douglas K. McCarty and Ben A. van der Pluijm. Influence of mechanical compaction and clay mineral diagenesis on the microfabric and pore-scale properties of deep water Gulf of Mexico mudstones

William J. Likos and Ning Lu. Pore-scale analysis of bulk volume change from crystalline swelling in $\mathrm{Na}^{+}$- and $\mathrm{Ca}^{2+}$-smectite 